\title{
GENDER PREFERENCES FOR ALTERNATIVE ENERGY TRANSPORT WITH FOCUS ON ELECTRIC VEHICLE
}

\author{
${ }^{1}$ Nirupama Prakash, ${ }^{2}$ Rashmi Kapoor, \\ ${ }^{3}$ Ajay Kapoor and ${ }^{4}$ Yashpal Malik \\ ${ }^{1,4}$ Amity Institute of Social Sciences, Amity University UP, India \\ ${ }^{2}$ Swinburne University of Technology, Hawthorn, Australia \\ ${ }^{3}$ International Research Engagement, \\ Swinburne University of Technology, Hawthorn, Australia
}

Received 2014-08-25; Revised 2014-09-20; Accepted 2014-09-23

\begin{abstract}
Transportation has become an important part of our day to day life. Due to changing lifestyle, frequent travels whether related to work or leisure has become a common phenomenon. Such lifestyle also demands comfortable transport medium and reasonable availability of fuels. As need of vehicle for transportation is rising, it has put pressure of fuel supply, fuel prices and environment as well. The rising prices of fuel, increasing pressure on resources and threatening environment pollution is driving the need for alternative and clean sources of energy. Increasing competition among nations to own the resources is becoming a serious threat for many developing countries. This paper empirically examines the gender preference for alternative energy sources and related technologies for vehicles. In total, 1168 questionnaires were received from respondents (male-711, female-442, not disclosed-15) from eleven cities in India viz. Bengaluru, Chennai, Cochin, Coimbatore, Hyderabad, Pune, Imphal, Rohtak, Sagar and Tiruvanathpuram in India and one city from Bhutan-Thimpu. Respondents who did not disclose their gender were excluded from the study. The study was conducted from October 2013 to June 2014. The objective of the study was to understand the social dimensions and gender preferences of the respondents regarding their preference for electric vehicle as an alternative energy transport for personal and public use. The primary data was collected through a structured questionnaire. The data was analyzed through the Statistical Package for Social Science $\left(\right.$ SPSS $\left.^{\circledR}\right)$. Findings indicate that in general fueled vehicles are still preferred over electric vehicles. However there is a strong interest in electric vehicles. It was observed that more than $66 \%$ of the respondents in the age group of 18-30 can become prospective customers in the near future, if the electric vehicles meet their expectations. In this age group, 59\% of the respondents were male and $41 \%$ were female. Most of the respondents indicated that they would purchase the electric vehicle as it would save operating costs, it is environment friendly and less dependent on fossil fuel. It was observed that as compared to female, male respondents were more inclined towards the influential factors like fuel efficiency, safety, vehicle power and reliability and early availability of vehicle in the market. In all 93\% of respondents confirm that they are willing to pay the premium price and among them, $61 \%$ were male and $39 \%$ were female.
\end{abstract}

Keywords: Gender Preferences, Electric Vehicles, Attitudes and Perceptions, Environment, Alternative Fuel Vehicles, Education, Age Group, Income Group

\section{INTRODUCTION}

Conventional transportation technologies use fossil fuels as the main source of energy for vehicle propulsion.
However in the recent times, the rising prices of oil and petroleum products, along with environmental awareness, are forcing nations to look for alternative transportation technologies. Over the past few years,

Corresponding Author: Nirupama Prakash, Amity Institute of Social Sciences, Amity University UP, India 
high oil prices, fossil fuel depletion and climate change have accelerated the need for Alternative Energy Transports (AETs). Competition is also rising among automobile companies; and they are on a continuous quest for developing more sustainable vehicles in order to combat fuel costs and the harmful environmental effect of petroleum products.

In India also, a new generation of quality conscious, price conscious and environment conscious consumer has evolved. The younger generation, especially in the age group of 18-30, is on one hand technology savvy and on the other hand conscious about making investment. A customer today has become conscious and believes in intelligent purchasing. The decision is dependent on thorough research and market responses.

A study was conducted by involving 1168 respondents belonging to different age groups. Persons from various companies, colleges and universities were asked about their views on a range of transportationrelated issues and their level of acceptance of new technologies. It was found that the most promising target group for the adoption of Alternative Energy Transports (AETs) is that of young, well-educated and environmentally aware people, who have the option of charging their car at home, who do not travel long distance in the city and need a small car. Out of these 1168 respondents, 15 respondents did not disclose their gender and were excluded from the study.

Dependence on the vehicle alternatives, environmental awareness and budget constraints for purchasing the second vehicle, reputation and reliability of vehicle, joint decision in buying, willingness to pay substantial amounts for the cost of environmental friendly fuel, driving range, pollution, vehicle-tax exemptions are also important factors influencing the purchase of an Alternative Energy Transportation (AETs).

A conclusion was drawn based on the data and preference of people. It is clear that there is an awareness gap regarding the effect on health and global climate change as only a few people are aware of the rising pressure on depleting natural resources due to an increase in consumption. There is a need of creating awareness amongst the middle-aged segment. The Alternative Energy Transportation (AETs) vehicle will be accepted in the society only if it is fuel efficient, cost saving and pollution free.

\subsection{Objective}

The main objective of the study was to determine the consumer's preference for Alternative Energy
Transportation (AETs), buying decision and the greater difference in their use of vehicles.

\subsection{Literature Review}

Vehicle pollution has been a serious concern for the past few decades all over the world. The combination of a short supply of fossil fuel reserves, environmental pollution and volatility in crude oil prices has generated interest for using alternative fuels. In his book "Alternative Fuels for Transportation", (Arumugam and Ramadhas, 2011) discusses the case of zero emission vehicles in three chapters, electric vehicles, fuel cells and hybrid vehicles. He discusses that based on the available energy sources, the battery electric vehicle and fuel cell electric vehicle cannot compete with the internal combustion engine vehicles in terms of driving range or initial cost. In the future according to his research, the hybrid electric vehicle (commonly called the hybrid vehicle) is not only a major class of alternative fuel vehicles, but also a practical solution for commercialization of super ultra-low emission vehicles.

The continued growth in the amount of imported oil required to meet demand for petroleum products threatens national and economic security and is not sustainable in the long term. Accordingly, the U.S. government has been adopting a wide range of policies to reduce energy consumption in the transportation sector since the energy crisis of 1973, such as reducing individuals' dependence on personal vehicles and promoting higher average vehicle fuel economies. For the past forty years, United States Presidents have repeatedly called for a reduction in the country's dependence on fossil fuels in general and foreign oil specifically. Stronger efficiency standards and higher taxes on motor fuels are a step in this direction, but achieving even greater reductions in oil consumption will require changing the way Americans power their transportation system. The Obama administration has, for example, embraced a goal of having one million electric-powered vehicles on U.S. roads by 2015 , while others proposed a medium-term goal where electric vehicles would consist of $20 \%$ of the passenger vehicle fleet by 2030-approximately 30 million electric vehicles (Lee and Lovellette, 2011).

This will include a multi-billion dollar investment in automotive battery manufacturing, tax credits and loans for plug-in vehicle manufacturing and purchase and research initiatives. Some states have adopted their own initiatives as well (Hidrue et al., 2011).

Alternate Fuel Vehicles (AFVs) have been appealing transportation technologies in the U.S. since 1990. The 
public and private sectors have invested billions of dollars into the development of AFVs. At this time, a few types of AFVs are on the roads in the U.S and some demonstration plans for AFVs are in process. These vehicles are potential substitutes for current gasoline vehicles and may account for a considerable share of the automobile market in the future. Conversely, it is also possible that some types of AFVs will die out since they fail to meet the requirements of potential consumers and hence do not achieve sufficient market share to be viable. However, how AFVs behave in the market depends on a variety of endogenous and exogenous factors, such as their performance, their limitations, consumer preferences, the regulatory environment, the price and availability of gasoline and so on. Therefore, it is difficult to forecast the market penetration of various AFVs. Yet, the forecasts of AFVs' market are essential to evaluating their potential contributions to the reduction of energy consumption and emissions in the transportation sector.

It is widely accepted that electrification of the transport sector is one of several technological trajectories that could redress some of the environmental issues associated with the growth in travel demand including climate change and oil demand at a global scale and air quality and noise pollution at the urban scale. Electric vehicles have been considered a promising technology at repeated intervals over the last century, but this promise has not been realized (Steinhilber et al., 2013). More importantly, the EV's ability to expand its niche market to a mass market would depend on dramatic advances in technology aimed at lowering the cost of battery production while maintaining high vehicle performance (Tsang et al., 2012). In most countries, however, lack of renewable electric energy is one of two important arguments making electric charging of batteries into a disputable global warming reduction action (Hjorthol, 2013). EV is a significant new technology; this makes it pertinent to explore EV adoption as "new technology" adoption (Jabeen et al., 2012).

Electric Vehicle (EV) is considered as an alternative which can potentially reduce the environmental impact substantially in contrast to cars powered by fossil fuel (Liao, 2014). Electric vehicles historically predate gasoline vehicles, but only received mainstream interest in the last decade (Avci et al., 2012). EVs have the potential to deliver significant GHG emission savings in road transport in a costeffective way, particularly after 2030 (Contestabile et al., 2012). It is expected that electric vehicles will be available especially for driving short distance for individual transport due to the limited range of the batteries and drive systems (Hanke et al., 2014).

For any product or service, information is one of the most important resources that one must collect. When it comes to consumer preferences, it becomes difficult concept to grasp. It was realized that consumer preferences can be effectively measured and their research may provide a deeper understanding of the choices that consumers make when deciding to select an offer against another and when deciding to continue in time the relationship with one supplier (Voicu, 2013). Concerns have been expressed by manufacturers and customers about the environmental impact of products during recent decades. Various studies support the assertion that consumers today prefer environmentally safe products and have a positive disposition towards companies following such practices (Bhatia and Jain, 2013).

\section{MATERIALS AND METHODS}

Our approach towards gaining an understanding of consumer preferences entailed developing a survey instrument for collecting individual data on the important variables. The primary research instrument used was a detailed questionnaire. This was used for data collection because it provides the most efficient means of collecting quantitative data on the major variables for a large cross section of population. The questionnaire was administered by the research team in various schools, colleges and corporates to get diversified views on the various variables. Information available on internet was also referred to, for better understanding of the subject.

The development of the questionnaire was a complex and lengthy process. It was designed after conducting various focus group discussions and interviews with professors, community members and transport industry representatives. On the basis of the focus group discussions and literature review, scales measuring attributes of transportation were developed and evaluated. After completion of various versions, the final version was designed and used in the metros or tier- 1 and tier -2 cities in the southern part of India and Thimpu-Bhutan.

The survey includes demographic characteristics of people, vehicle attributes, environmental impacts, technological issues and detailed information on daily travel. Demographic variables like gender, age, household income and education level were taken for understanding the consumer preferable attributes. The data reveals that male respondents drive $30 \mathrm{~km}$ on an 
average $19 \%$ more than their female counterparts (male $44 \%$ and female 25\%). Overall, the $\mathrm{km}$ driven daily decrease as the age group increases. In our survey we observed that $68 \%$ of respondents were from the age group of $18-30$, whereas $29 \%$ belonged to the age group of 31-60.

Along with the demographic information such as gender, age, education and income, respondents were also asked to share their views on transportation issues faced by them. Questions were asked about the environment, technology used and environmental impact of motor vehicles. Vehicle related questions included their vehicle ownership and factors that might influence their purchase decision.

\section{DATA ANALYSIS}

The descriptive responses were collected and the questionnaires were analyzed by using frequency distribution and descriptive statistics in Statistical Package for the Social Science (SPSS version 20) software. All incomplete surveys were discarded from the analysis. Frequency tables and descriptive statistics were constructed to display results with respect to each of the research question.

\section{RESULTS}

\subsection{Transportation Issues}

To understand the transport related issues, the respondents were asked questions related to problems faced by them. This included questions on congestion, noise level, pollution, safety, fuel import etc. This helped to develop a better understanding of respondents' attitude toward transportation. "Figure 1" presents the response of gender on various transport related issues. In terms of percentage male and female were almost similar with just a variation of $4-5 \%$ which means that male and female both are sensitive about transport issues as explained in Table 1". Importing of fuel is a problem or major problem for male and female equally in terms of percentage.

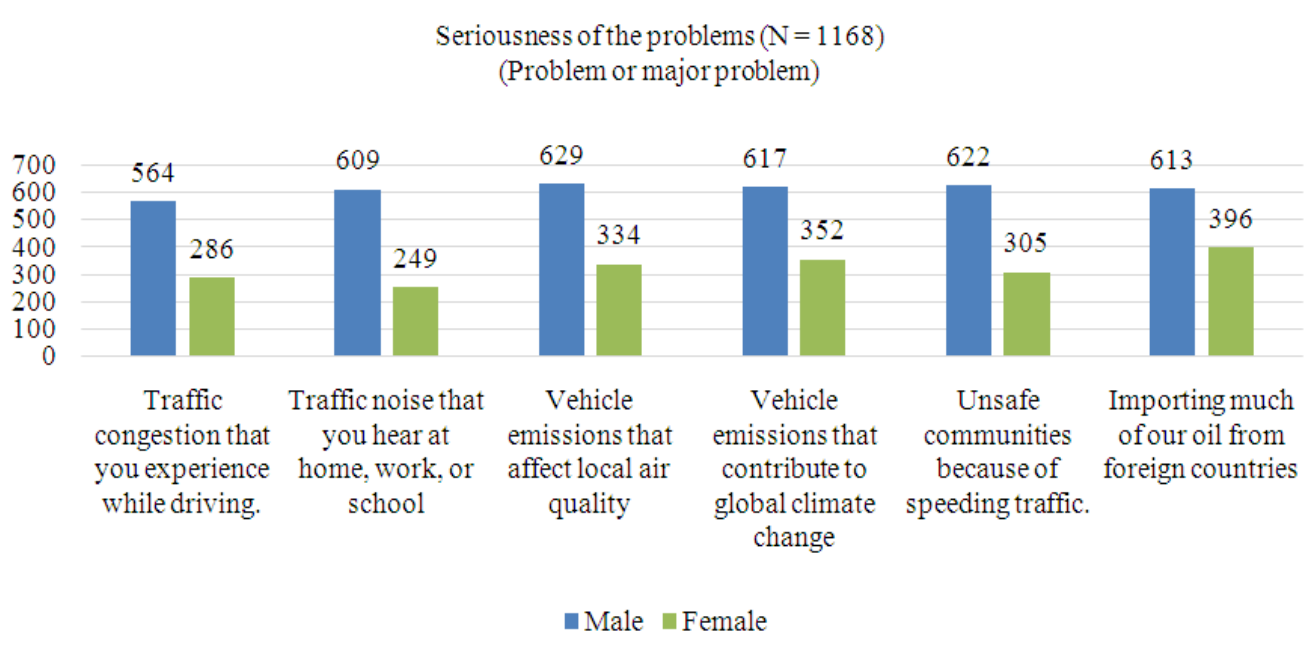

Fig. 1. Break-up of major transport issues based on gender. Respondents included 711 males and 442 females

Table 1. Break-up of major transport issues based on gender

Seriousness of the problem (problem or major problem)

\begin{tabular}{|c|c|c|c|c|}
\hline \multirow[b]{2}{*}{ Factors } & \multicolumn{2}{|l|}{ Male } & \multicolumn{2}{|l|}{ Female } \\
\hline & Frequency & Percentage & Frequency & Percentage \\
\hline Traffic congestion that you experience while driving. & 564 & 81 & 361 & 83 \\
\hline Traffic noise that you hear at home, work, or school & 609 & 87 & 399 & 92 \\
\hline Vehicle emissions that affect local air quality & 629 & 90 & 403 & 93 \\
\hline Vehicle emissions that contribute to global climate change & 617 & 89 & 402 & 92 \\
\hline Unsafe communities because of speeding traffic. & 622 & 90 & 402 & 93 \\
\hline Importing much of our oil from foreign countries & 613 & 88 & 381 & 88 \\
\hline
\end{tabular}




\subsection{Impact on Environment}

It was observed in "Table 2" that male and female both are sensitive about the transport issues which has an impact on environment with just a variation of $1-2 \%$. It was observed that there is no difference between the thoughts of gender when the question was asked related to greenhouse gases. Male and female equally (in terms of total percentage) consider that cars, minivans, vans, pickups and SUVs are an important source of the greenhouse gases that many scientists believe are responsible for global warming. It was also observed that almost $15-20 \%$ of the respondents are not concerned about environmental impact which is caused by various transport vehicles. Almost $30-40 \%$ of respondents think that small cars are not the reason behind air pollution. "Figure 2" presents gender-wise view related to impact on environment by various transport modes.

\subsection{Reasons in Support of Electric Vehicles in Future (Part 1)}

“Table 3" presents that out of total respondents, 79\% of male agreed that saving money on the cost of operation is very important or important while $84 \%$ female said that it is important or very important. $89 \%$ said that electric vehicles are very important or important for reducing the harmful impact (pollution) on the environment, while 93\% female said that they are very important or important. $90 \%$ of male said that it is important to reduce the dependence on gasoline, $92 \%$ female said that it is important. $89 \%$ of male and female were interested to drive a vehicle with more advanced or innovative technology and said that it is an important factor which they will consider in the future for buying the electric vehicle.

It was observed in "Fig. 3"that female respondent were marginally more sensitive about the purchasing factors in-comparison to male respondent.

\subsection{Reasons in Support of Electric Vehicle in Future (Part 2)}

When asked to list some of the important factors which would restrict a customer from buying the Alternative Energy Transportation (AETs), the common issues were concern about recharge stations, higher price, availability of desirable vehicle size, reliability, ongoing maintenance, operating costs and the ability to carry occasionally heavy loads as explained in "Fig. 4". In each case it was found that these above mentioned factors are important or very important for more than $80 \%$ of the respondents. It was observed that females were marginally more selective than the male respondents while selecting important factors in terms of percentage as explained in "Table 4".

\section{Views about the Environmental Impact \\ (Agree with the statement)}

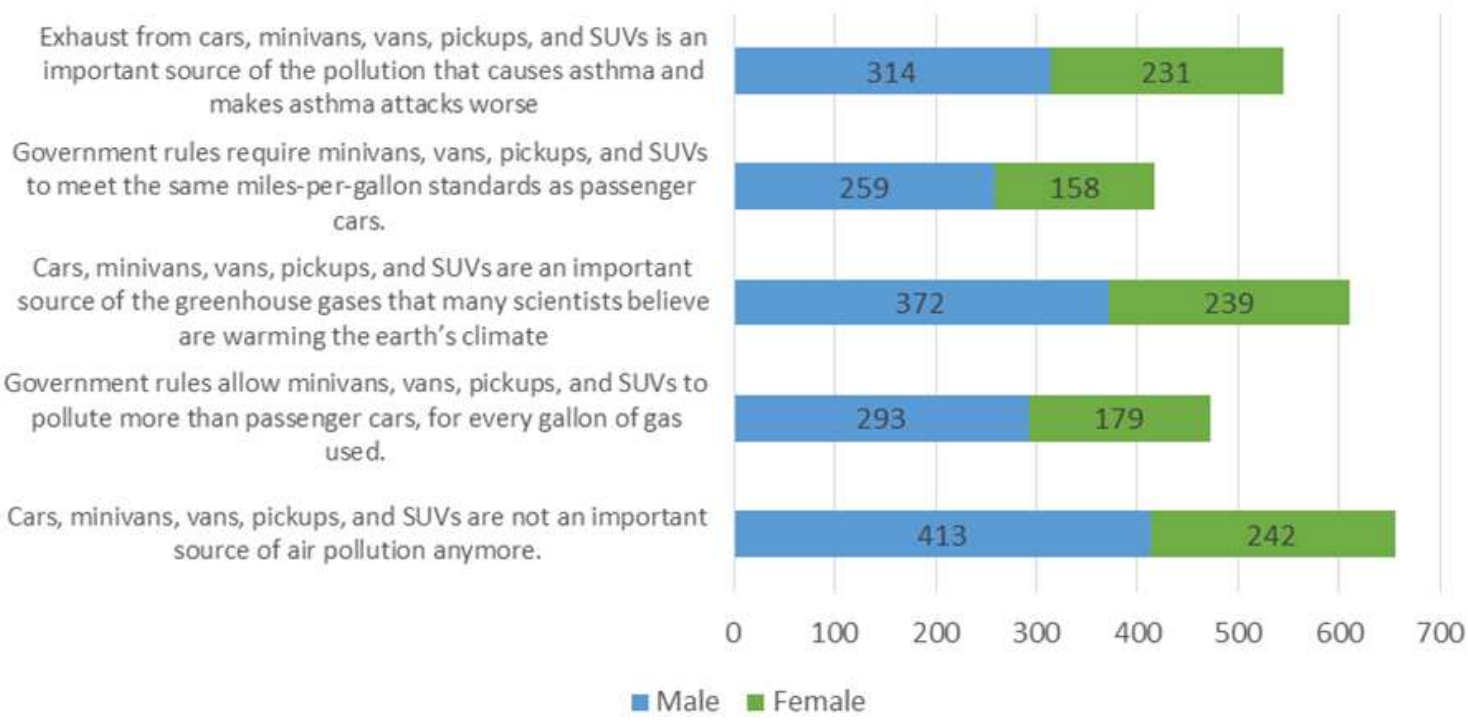

Fig. 2. Gender-wise view-impact on environment of various transport modes. Respondents included 711 males and 442 females 


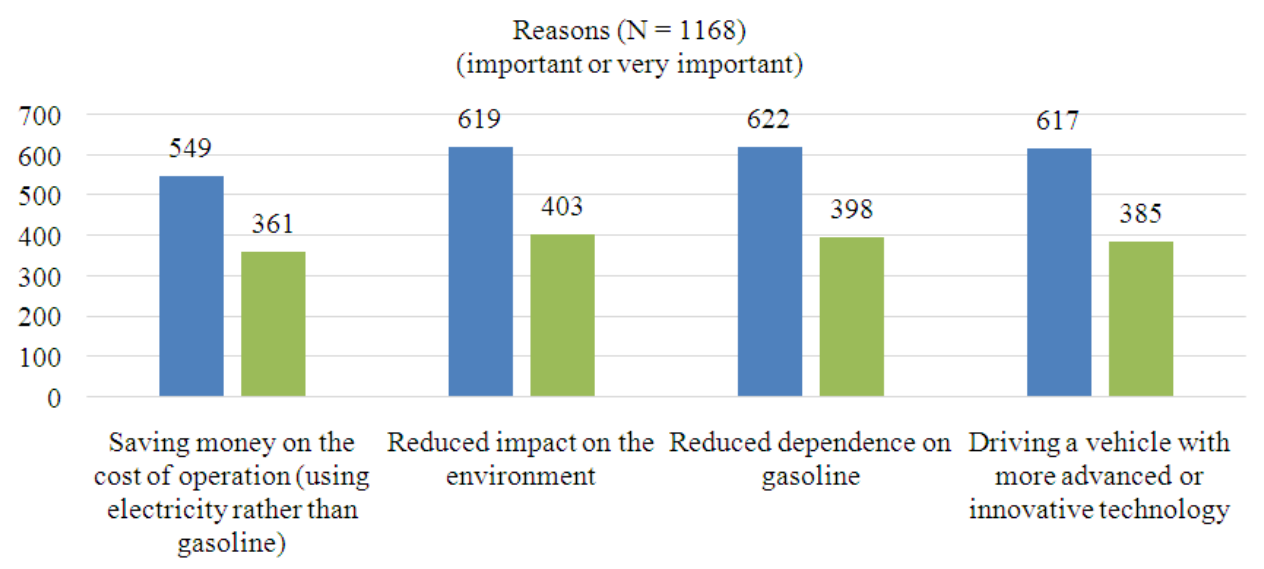

Male $\square$ Female

Fig. 3. Responses in support of electric vehicles in future-gender preference. Respondents included 711 males and 442 females

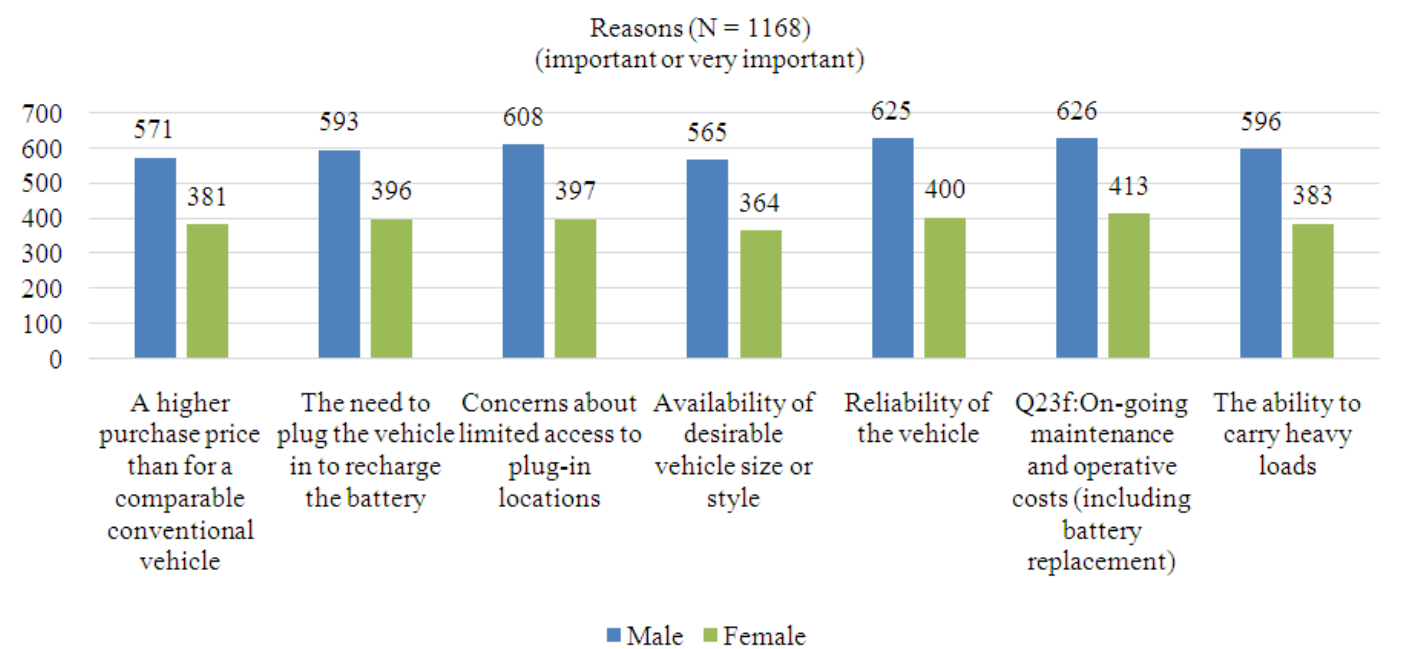

Fig. 4. Factors supporting purchase of electric vehicles-gender preferences. Respondents included 711 males and 442 females

Table 2. Gender-wise view-impact on environment of various transport modes

\begin{tabular}{|c|c|c|c|c|}
\hline \multirow[b]{2}{*}{ Factors } & \multicolumn{2}{|l|}{ Male } & \multicolumn{2}{|l|}{ Female } \\
\hline & Frequency & Percentage & Frequency & Percentage \\
\hline $\begin{array}{l}\text { Cars, minivans, vans, pickups and SUVs are not } \\
\text { an important source of air pollution anymore. }\end{array}$ & 413 & 60.8 & 242 & 56.0 \\
\hline $\begin{array}{l}\text { Government rules allow minivans, vans, pickups and SUVs } \\
\text { to pollute more than passenger cars, for every gallon of gas used. }\end{array}$ & 293 & 43.3 & 179 & 41.7 \\
\hline $\begin{array}{l}\text { Cars, minivans, vans, pickups and SUVs are an important } \\
\text { source of the greenhouse gases that many scientists } \\
\text { believe are warming the earth's climate }\end{array}$ & 372 & 55.1 & 239 & 55.2 \\
\hline $\begin{array}{l}\text { Government rules require minivans, vans, pickups and SUVs } \\
\text { to meet the same miles-per-gallon standards as passenger cars. }\end{array}$ & 259 & 38.4 & 158 & 36.7 \\
\hline $\begin{array}{l}\text { Exhaust from cars, minivans, vans, pickups and SUVs is an } \\
\text { important source of the pollution that causes asthma } \\
\text { and makes asthma attacks worse }\end{array}$ & 314 & 46.2 & 231 & 53.3 \\
\hline
\end{tabular}




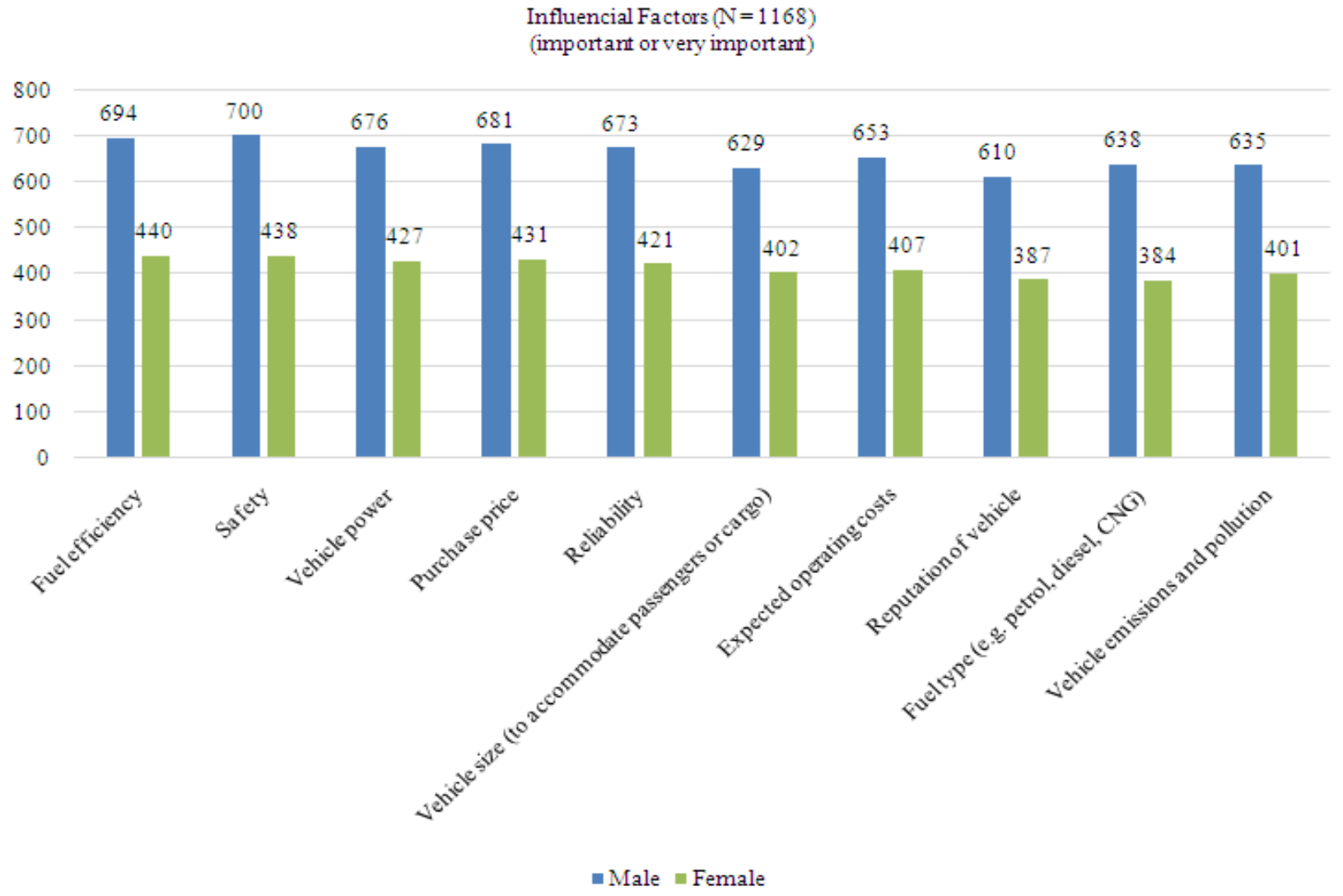

Fig. 5. Factors important for purchase of personal vehicles. Respondents included 711 males and 442 females

Table 3. Responses in support of electric vehicles in future-gender preference

\begin{tabular}{|c|c|c|c|c|}
\hline \multirow[b]{2}{*}{ Factors } & \multicolumn{2}{|l|}{ Male } & \multicolumn{2}{|l|}{ Female } \\
\hline & Frequency & Percentage & Frequency & Percentage \\
\hline Saving money on the cost of operation (using electricity rather than gasoline) & 549 & 79 & 361 & 84 \\
\hline Reduced impact on the environment & 619 & 89 & 403 & 93 \\
\hline Reduced dependence on gasoline & 622 & 90 & 398 & 92 \\
\hline Driving a vehicle with more advanced or innovative technology & 617 & 89 & 385 & 89 \\
\hline
\end{tabular}

Table 4. Factors supporting purchase of electric vehicles-gender preferences

\begin{tabular}{|c|c|c|c|c|}
\hline \multirow[b]{2}{*}{ Factors } & \multicolumn{2}{|l|}{ Male } & \multicolumn{2}{|l|}{ Female } \\
\hline & Frequency & Percentage & Frequency & Percentage \\
\hline A higher purchase price than for a comparable conventional vehicle & 571 & 83 & 381 & 89 \\
\hline The need to plug the vehicle in to recharge the battery & 593 & 86 & 396 & 92 \\
\hline Concerns about limited access to plug-in locations & 608 & 89 & 397 & 93 \\
\hline Availability of desirable vehicle size or style & 565 & 82 & 364 & 84 \\
\hline Reliability of the vehicle & 625 & 91 & 400 & 93 \\
\hline On-going maintenance and operative costs (including battery replacement) & 626 & 92 & 413 & 96 \\
\hline The ability to carry heavy loads & 596 & 87 & 383 & 88 \\
\hline
\end{tabular}


Table 5. Factors important for purchase of personal vehicles

\begin{tabular}{|c|c|c|c|c|}
\hline \multirow[b]{2}{*}{ Factors } & \multicolumn{2}{|l|}{ Male } & \multicolumn{2}{|l|}{ Female } \\
\hline & Frequency & Percentage & Frequency & Percentage \\
\hline Fuel efficiency & 694 & 98.58 & 440 & 100 \\
\hline Safety & 700 & 99.29 & 438 & 100 \\
\hline Vehicle power & 676 & 96.16 & 427 & 98 \\
\hline Purchase price & 681 & 96.87 & 431 & 98 \\
\hline Reliability & 673 & 95.73 & 421 & 97 \\
\hline Vehicle size (to accommodate passengers or cargo) & 629 & 89.99 & 402 & 92 \\
\hline Expected operating costs & 653 & 93.02 & 407 & 93 \\
\hline Reputation of vehicle & 610 & 88.15 & 387 & 91 \\
\hline Fuel type (e.g., petrol, diesel, CNG) & 638 & 91.14 & 384 & 88 \\
\hline Vehicle emissions and pollution & 635 & 90.46 & 401 & 92 \\
\hline
\end{tabular}

\subsection{Factors Important for Purchase of Personal Vehicles}

The respondents showed their concerns for fuel efficiency, safety, vehicle power, vehicle reliability, size of the vehicle, expected operating costs (for maintenance and repair), reputation of a particular vehicle make or model, fuel type (e.g. petrol, diesel, CNG), vehicle emission and pollution as explained in "Fig. 5". Most of the respondents shared that they would consider all the above mentioned points to a large extent while deciding which new vehicle to purchase and consider them important in terms of percentage as explained in "Table 5".

\section{CONCLUSION}

The views of all the respondents who participated in the survey were analyzed and hence conclusions based on the responses were derived. This section summarizes the key findings and presents some recommendations based on the responses.

The survey was conducted in universities and hence more than $65 \%$ of the respondents were in the young age group of $18-30$. It was observed that only $4 \%$ of male and $1 \%$ of female respondents have electric vehicle at their home. Out of the respondents who do not have electric vehicle at their home, $58 \%$ were male and $37 \%$ were female. More than $66 \%$ of respondents were interested in buying the new electric vehicle once it is available in the market, of which male \% was 40 and female $\%$ was 26 . If this group is targeted properly and made aware of the usefulness of electric vehicles, this group can easily become prospective buyers of electric vehicles. They can be potential customers in future.

Television, newspaper, internet and magazine were the main source of information about new technologies for majority of the respondents. Very few respondents get information from radio and other sources. Around $91 \%$ of the respondents shared that they purchase a vehicle after discussing it with their family members, relatives and friends. Such respondents prefer to take a joint decision for the purchase of a new vehicle.

Most of the respondents expressed desire to purchase electric vehicle as it will save on operating cost, it is environment friendly and less dependent on fuel. It was also observed that female is marginally more sensitive than the male respondents towards environmental factors. The survey also revealed that almost $93 \%$ of the customers are even willing to pay a premium for a hybrid vehicle. This clearly shows that demand of fuel efficient hybrid vehicle exists in the market.

After a detailed analysis of the survey result, it was concluded that people are willing to purchase an electric vehicle which is powerful, reliable, fuel efficient and safe.

It was further observed that there is lack of awareness among people on important issues such as link between using a vehicle causing pollution and its hazardous effects on health and global climate change. Due to this lack of awareness, environmental issues play a limited role in the decision making process while buying a new vehicle.

\section{RECOMMENDATION}

After analyzing customer response and preference through survey, it was strongly felt that Alternative Energy Transports (AETs) could be made more acceptable by focusing on consumer preferences and vehicle characteristics i.e. good power, reliability, fuel efficiency and safety. It is necessary to educate and sensitize the public on AETs especially electric vehicles to increase its acceptance and usage, so that a positive transition can take place which will help in bringing energy security, air quality, public health and economic benefits to India. 
Therefore, significant investment in research and development is required to improve the perception and popularity of Alternative Energy Transportation (AETs) such as Electric Vehicles. Government subsidies, procurement programs and development of niche markets, all will have a role to play in encouraging the uptake of the new technology.

\section{ACKNOWLEDGMENT}

The researchers thank Swinburne University of Technology, Melbourne, Australia and Amity University, Noida, Uttar Pradesh for providing the academic support to this study. Due acknowledgement is also made to AutoCRC ${ }^{\circledR}$ Ltd, Port Melbourne, Australia for providing financial support for this study.

\section{REFERENCES}

Arumugam, S. and Ramadhas, 2011. Alternative fuels for transportation. 1st Edn., Taylor and Francis, London.

Avci, B., K. Girotra and S. Netessine, 2012. Electric vehicles with a battery switching station: Adoption and environmental impact. INSEAD. France.

Bhatia, M. and A. Jain, 2013. Green marketing: A study of consumer perception and preferences in India. Electronic Green J.

Contestabile, M., G. Offer and R. North, 2012. Electric vehicles: A synthesis of the current literature with a focus on economic and environmental viability. LCAworks. London.
Hanke, C., M. Hülsmann and D. Fornahl, 2014. SocioEconomic Aspects of Electric Vehicles: A Literature Review. In: Evolutionary Paths Towards the Mobility Patterns of the Future, Michael Hülsmann and Dirk Fornahl (Eds.)., Springer Berlin Heidelberg, ISBN-10: 364237557X, pp: 13-36.

Hidrue, M., G. Parsons, W. Kempton and M. Gardner, 2011. Willingness to pay for electric vehicles and their attributes. Resource Energy Econom., 33: 686705. DOI: $10.1016 /$ j.reseneeco.2011.02.002

Hjorthol, R., 2013. Attitudes, ownership and use of electric vehicles: A review of literature. National Academy of Sciences.

Jabeen, F., D. Olaru, B. Smith, T. Braunl and S. Speidel, 2012. Acceptability of electric vehicles: Findings from a driver survey. Transport Research Board of the National Academics. Perth.

Lee, H. and G. Lovellette, 2011. Will electric cars transform the U.S. vehicle market? Belfer Center for Science and International Affairs, Cambridge.

Liao, F., 2014. Chinese consumer preferences for electric vehicles. Delft University of Technoloogy. China.

Steinhilber, S., P. Wells and S. Thankappan, 2013. Socio-technical inertia: Understanding the barriers to electric vehicles. Energy Policy, 60: 531-539. DOI: $10.1016 /$ j.enpol.2013.04.076

Tsang, F., J. Pedersen, S. Wooding and D. Potoglou, 2012. Bringing the electric vehicle to the mass market. Rand Europe, Cambridge, U.K.

Voicu, M., 2013. Characteristics of the Consumer Preferences Research Process. Nicolae Titulescu University. 